\title{
Philosophical Intuition Is the Capacity to Recognize one's Epistemic Position. An Old-Fashion Approach Based on Russell, Carnap, Wittgenstein, and Husserl
}

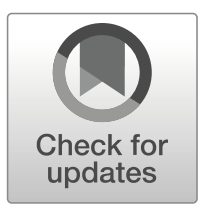

\section{Konrad Werner ${ }^{1}$}

Received: 5 August 2019 / Revised: 5 August 2019 / Accepted: 18 February 2020 /

Published online: 11 May 2020

(C) The Author(s) 2020

\begin{abstract}
Philosophical intuition has become one of the most debated problems in recent years, largely due to the rise of the movement called experimental philosophy which challenged the conviction that philosophers have some special insight into abstract ideas such as being, knowledge, good and evil, intentional action, etc. In response to the challenge, some authors claim that there is a special cognitive faculty called philosophical intuition which delivers justification to philosophical theses, while some others deny it based on experimental results. A relatively smaller group of researchers aim at clarifying what the alleged intuition is. I follow the latter path. In this paper I argue that philosophical intuition is in the first place the capacity enabling one to what I refer to as the recognition of one's epistemic position. The latter means becoming aware of the seemingly trivial "fact" that the way in which the world manifests itself depends on the cognitive apparatus one has, thereby propelling one to draw a distinction between appearances and reality. The recognition at stake is a very specific capacity to approach the world solely as it is experienced. This capacity, I argue, is the core and the defining feature of philosophical intuition. As part of my argumentation I also distinguish between the intuition in question and its different manifestations; and then introduce a novel notion of erotetic intuition. My argument is called "old-fashion" to emphasize the fact that I draw mostly on four figures who were pivotal in the twentieth- century philosophy and whose influence on the current debate concerning philosophical intuition should be, I believe, stronger than it is; I mean Russell, Carnap, Wittgenstein, and Husserl.
\end{abstract}

Keywords Philosophical intuition - Expertise defense $\cdot$ Experimental philosophy $\cdot$ Analytic philosophy · Russell · Carnap · Wittgenstein · Husserl

Konrad Werner

k.werner2@uw.edu.pl

1 University of Warsaw, Institute of Philosophy, ul. Krakowskie Przedmieście 3, 00-927 Warszawa, Poland 


\section{Introduction: The "most trivial fact" and its Recognition"}

A minded creature faces a certain image of the world (a "manifest image" as Sellars 1956 called it). Being an image, it first of all depends on the creature's cognitive apparatus, and could therefore be different. Secondly, it should be distinguished from what it is an image of, i.e., the supposed reality in itself. Tim Crane provides an apt description of this seemingly trivial "fact":

The minded creature is one for which things are a certain way: the way they are from that creature's perspective. A lump of rock has no such perspective, the daffodil has no such perspective. We might express this by saying that a minded creature is one which has a world: its world. Its having a perspective consists in its having a world. Having a world is something different from there simply being a world. It is true of the rock or the daffodil that it is part of the world; but it is not true that they have a world (...). But to say that a creature with a perspective has a world is not to say that each creature with a perspective has a different world. Perspectives can be perspectives on one and the same world (Crane 2001: 4).

I will argue here that being aware of this trivial "fact" is the very essence of philosophical competence. Becoming aware of it is referred to as the recognition of one's epistemic position in this paper (I introduce this notion and discuss it in greater detail elsewhere; see Werner 2016). I propose that it is possible to gain such awareness, thus to recognize one's epistemic position thanks to a specific intellectual faculty. This specific faculty is none other than philosophical intuition, which has lately given rise to lively discussions.

The mentioned discussion on philosophical intuition was sparked by the emergence of so-called experimental philosophy (hereafter Xphi), a research program whose aim is to study common intuitions and beliefs about knowledge, intentionality, good and evil, what is justified and what is unjustified, etc. - in other words, common intuitions regarding abstract issues or concepts that professional philosophers study (see e.g. Nadelhoffer and Nahmias 2007; Kauppinen 2007; Prinz 2008; Knobe and Nichols 2008, 2017; Knobe et al. 2012; Alexander 2012; Beebe 2012; Woolfolk 2013; Knobe 2015; Sorel 2018). This also gave rise to the question whether - and if so, under what conditions - the intuition of a professional philosopher is more reliable when it comes to such abstract matters. Thus the question about the expertise of the philosopher emerged (see Weinberg 2007; Swain et al. 2008; Deutsch 2010; Tobia et al. 2013; Nado 2014, 2016; Rini 2015; Egler and Ross 2018).

It has become quite common lately to defend traditional philosophy using the expertise defense which states that only a properly trained philosophical intuition supplies findings that are binding in the field. Drawing on the idea of philosophical intuition as the ability to recognize one's epistemic position, I shall propose a new understanding of the expertise defense. While it should not essentially be aimed at

\footnotetext{
${ }_{1}^{1}$ This study was possible due to the grant 2016/20/S/HS1/00046 provided by the National Science Centre (Narodowe Centrum Nauki), Poland. I am grateful to Katarzyna Paprzycka-Hausman and to all my colleagues from the epistemology department at the University of Warsaw, for their hospitality, insightful remarks, and encouragement. Some of the ideas set forth in this paper were presented during the Buffalo Annual Experimental Philosophy Conference in 2017. I am grateful for the feedback I got there.
} 
showing that the beliefs of non-philosophers are in some sense inferior to philosophical beliefs in the strict sense, there are definitely reasons why these two sets of beliefs cannot properly be set on an equal footing.

This paper is not a voice against Xphi. Instead, the latter sets a background against which the issue of philosophical intuition thought of as a specific intellectual faculty or a generator of specific contents stands out clearly. I shall reformulate the expertise defense in the last section, while at the same time I believe that Xphi could adjust its methods and general approach in order not to be vulnerable to the argument. This is, however, a material for a different paper.

I shall roll our my proposal stepwise, starting from more general considerations concerning the concept of philosophical intuition. I shall distinguish between the intuition proper and its manifestations. Then, I introduce the notion of erotetic intuition which is, in short, the capacity to problematize a given domain or issue; in simple terms - to ask questions. After a short discussion concerning the specificity of philosophical questions (and answers), I propose to make use of the notion of recognition of one's epistemic position, presented as a factor establishing the proper reference domain for the pursuit of philosophizing.

I call this investigation "old-fashion," meaning that it owes much to several philosophers who are deemed classics but rarely cited when it comes to the controversies surrounding Xphi and the concept of philosophical intuition. I mean figures such as Bertrand Russell, Rudolf Carnap, Ludwig Wittgenstein, and Edmund Husserl. I hope to prove that this omission is not beneficial, while bringing them back to the table is.

\section{Experimental Philosophy and the Question of Philosophical Intuition}

Xphi has become a very diverse movement. The group of researchers identifying themselves as experimental philosophers targets such issues as knowledge, skepticism and contextualism (Weinberg et al. 2001; Nichols et al. 2003; Buckwalter 2010, 2012; Brown 2011; Starmans and Friedman 2012; Buckwalter and Schaffer 2015; Machery et al. 2015; Roberts et al. 2017); intentional action (Knobe 2003; Nichols and Ulatowski 2007; Paprzycka 2015); semantics (Machery et al. 2004; Machery 2012), among many others. While in most cases the experiments at stake take nonphilosophers as their targets, some studies are dedicated to eliciting the intuitions of professional philosophers, too, and to comparing them with the intuitions of the folk (Kuntz and Kuntz 2011; Livengood et al. 2010; Schwitzgebel and Rust 2009; Schwitzgebel and Cushman 2012, 2015).

The emergence of the Xphi program caused a kind of crisis in the field of metaphilosophy (Baz 2017). If each of us is capable of such intuitive approaches to the problem of knowledge, intentionality, or morality, then on what basis does a traditional philosopher claim to have special expertise when it comes to these issues?

Being challenged by Xphi, some "traditional" philosophers questioned the experimentalists' claim that the results of Xphi are relevant to philosophy itself. They argued that in order to ponder philosophical problems one must have an appropriate background, in the same way that one needs to have an appropriate background in order to perform research in physics or mathematics. Therefore, as some traditionalists claim, the philosophical intuitions of people who are not properly trained are of no use to a 
professional epistemologist or ethicist. Similarly, it would be pointless for a physicist to conduct a survey on the principles of thermodynamics among passers-by. This strategy of defending traditional philosophy is referred to as the expertise defense. Its prominent representatives include Timothy Williamson $(2004,2007,2011)$ and Kirk Ludwig (2007; see also Sosa 2006; Machery 2011, Nado 2014).

In response to the analogy proposed above, the Xphi supporter will point out that a physicist, even if some kind of intuition can be attributed to them and even if this intuition does not need to be consulted with anyone outside the circle of professional physicists, never has to recourse to this supposed capacity when justifying theorems. Physics has a well-defined formal-empirical set of methods and procedures for verifying and falsifying physical theorems. However, the consensus in Xphi is that in traditional philosophy intuition is not merely an auxiliary tool, but the proper reference when justifying claims (Cappelen 2012 argues against this view). Therefore, the question arises as to the nature of philosophical competence, understood as a kind of expertise, as opposed to ordinary conceptual intuitions. If the philosopher can be said to be an expert, what does his or her expertise consist in and how does it manifest itself? I shall try to answer this question, based on the idea of recognition of one's epistemic position.

\section{Preliminary Intuitions Regarding Philosophical Intuition}

Although there is no agreement on the nature of intuitions, it is widely accepted that they are "non-inferential," meaning that they - whether they are judgments or something else - "arise spontaneously in the mind, not as a result of deliberation or reasoning” (Rini 2015: 432). Hence, I accept a provisional characterization according which intuition is a "non-inferential" acquaintance with a certain content.

Elijah Chudnoff (2011) distinguishes between doxastic and perceptualist approaches to intuition. The former follows David Lewis (1983) who held that an intuition was nothing more than an opinion expressed in the form of a belief. So, intuitions are judgments or inclinations to judge (see e.g. Williamson 2004). According to Chudnoff this is the approach that Xphi subscribes to, at least in most cases. Meanwhile, perceptualist approaches maintain that "intuitions - like perceptual experiences - are predoxastic experiences that - unlike perceptual experiences - represent abstract matters as being a certain way. The idea is that in having an intuition, it seems to you that abstract matters are a certain way" (Chudnoff 2011: 626). Now, based on these special perceptions, one can come to some conclusions, thus articulate a judgment, but this is not part of the intuition proper.

The matter becomes even more complicated when one considers the fact that intuition is not confined to the domain of philosophy. The phenomenon of intuitive insight is studied in other fields, e.g., in mathematics (see Dehaene 2009). Aside from the question of what makes philosophical intuition intuition, there is the no less important question of what makes a given intuition philosophical rather than something else. These are the questions that I would like to address. Regardless of whether and how intuition manifests itself in other fields, and whether it makes sense to speak of intuition as such, that is, intuition without clear assignment to a discipline, I would like to propose a certain understanding of philosophical intuition. 
I wish to stay neutral when it comes to the doxastic vs. perceptualist distinction, although I lean more towards the latter for the reasons to be explicated. However, while I shall introduce a third approach, called erotetic intuition, I also wish to stress one thing that is missing in the debate. Namely, I propose distinguishing philosophical intuition from its various manifestations. It is a conceptual clarification that enables us to avoid pointless debates drawn on an unwarranted presupposition that there is only one true answer to the question of what intuition is.

Here is how the latter posit is substantiated. Think of the doxastic approach. Note that there are two different elements within the latter: for judgment is the product of a certain cognitive capacity or faculty, and when speaking of inclination to judge, it is this capacity that we can refer to. However, the very notions of inclination or, to put it in a somewhat Kantian way, the power of judgment are in fact theoretical postulates. The latter means that we never encounter the inclination to judge or the power/capacity/ faculty of judgment as such; we are only ever dealing with $a$ judgment, expressed in the form of a proposition by someone, which we interpret as a product of a particular inclination or capacity.

As far as experience is concerned, we face an analogous ambiguity: for we can think of experience as something concrete available to us immediately, that is, the product of a presumed sense or sensory capacity (the capacity of experiencing), of which we learn only when faced with its products, that is, the concrete experiences that fill our everyday lives. Thus, we assume that there is a sense or sensory capacity as such which produces actual perceptual experience. The capacity in question is a certain theoretical posit, too. Crucially, speaking of the sense is not equivalent to speaking of the relevant sense organ. The latter is part of our bodies, composed of proteins, among other things, and capable of receiving and processing a specific kind of energy, be it the energy carried by electromagnetic waves or mechanical waves, or the energy of chemical reactions. Speaking of the five senses refers, however, to knowledge or content generators somehow based on the physicochemical machinery just mentioned, but not identical to it (at least when conceptually analyzed). So, the senses or sensory capacities are theoretical postulates which are supposed to answer the question of how and why we experience the world the way we do and how the experience contributes to our knowledge of the outside world.

Bearing all this in mind, I would like to point out that when we talk about philosophical intuition understood as a specific faculty, we are also dealing with a certain posited entity, whose existence we learn of when some product available to us, whether a judgment or a conscious experience, requires a specific type of explanation and is not explained (or not completely) by invoking the sensory capacity as it usually functions and the capacity of judgment that produces everyday beliefs or scientific theses. I don't want to say, of course, that there a special, separate cognitive capacity responsible for philosophizing, alongside the sensory capacity and the capacity of judgment, granting some extraordinary insight; what I mean is that once philosophical intuition is taken under consideration in the first place, it should be provisionally targeted as a faculty responsible for generating specific content, or, in short, a as a specific generator of content, manifesting itself in the guise of experiences and judgments, possibly among other things.

Chudnoff (2011) argues that the difference between doxastic approaches and the perceptualist approaches is profound, because at the end of the day it concerns what 
there $i s$ : either there are pre-doxastic experiences or not, and this disagreement is not merely terminological - it is substantive, as Chudnoff puts it, or, as I would say, metaphysical. However, my attitude here is, say, more phenomenological. The latter is supposed to mean that prior to the metaphysics at stake, we should take all available manifestations of the alleged philosophical intuition as given and try to figure out how they work together, instead of deciding upfront which manifestation is true to the nature of the underlying cognitive capacity.

So, I would like to distinguish between the type of philosophical intuition that we are interested in here, i.e. a theoretically postulated faculty coming up with specific contents - say, a generator of specific contents - and various manifestations thereof; in other words - different deliveries of these contents, so to speak, be it a judgment or an experience, or something else. Based on that one can be a pluralist with respect to manifestations and focus one's attention on what constitutes the genuine puzzle in this context, namely the capacity itself: what is so special (if anything) about the postulated philosophical intuition and the contents it produces, independently of whether they become apparent to us in the form of an experience or judgment.

\section{A Special Skill or a Curse: Russell and Carnap on the Nature of Philosophizing}

So, what is so special about the contents produced and scrutinized by philosophers? Arguably there is a common wisdom according to which philosophers are skilled in taking the world we experience as a whole and in problematizing the most general issues which may be transparent, thus unnoticed from everyday perspective as well as from the perspective of various sciences which are focused on their empirically delineated segments or aspects of reality. For example, philosophers do not ask whether this or that empirical investigation can result in a piece of new knowledge, but under what conditions empirical knowledge as such can be gleaned.

Now, at some point there was a consensus within at least some philosophers, i.e., those who were very critical about their own discipline, that this specific level of generality and abstractness was also dangerous. Bertrand Russell expresses his concerns, among other places, in The Problems of Philosophy, a book I shall draw on in several places from this point on. Let me make use of several extensive quotes from this brilliant work as they clearly illustrate the line of thinking about philosophy that I wish to follow. At the same time, the book also shows a certain subtle tension I wish to flag, which is the core of the conception to be rolled out in this paper.

So, Russell expresses his reservation towards those philosophers, particularly "metaphysicians," who would approach the world en bloc and aim at nailing down its ultimate, true nature:

Most philosophers - or, at any rate, very many - profess to be able to prove, by a priori metaphysical reasoning, such things as the fundamental dogmas of religion, the essential rationality of the universe, the illusoriness of matter (...). This hope, I believe, in vain. It would seem that knowledge concerning the universe as a whole in not to be obtained by metaphysicians, and that the 
proposed proofs that, in virtue of the laws of logic, such and such things must exist and such and such others cannot, are not capable of surviving a critical scrutiny (Russell 1912/2004: 99).

Aiming at the world as a whole is a nonstarter, according to Russell. On the other hand, however, he himself points out that philosophy is not concerned with well-delineated fragments of reality, but with certain "ultimate questions." He starts his book with the following words:

Is there any knowledge in the world which is so certain that no reasonable man could doubt it? This question, which at first sight might not seem difficult, is really one of the most difficult that can be asked. When we have realised the obstacles in the way of a straightforward and confident answer, we shall be well launched on the study of philosophy - for philosophy is merely the attempt to answer such ultimate questions, not carelessly and dogmatically, as we do in ordinary life and even in the sciences, but critically, after exploring all that makes such questions puzzling, and after realizing all the vagueness and confusion that underlie our ordinary ideas (Ibid.: 1).

Then he adds in a different chapter:

The man who has no tincture of philosophy goes through life imprisoned in the prejudices derived from common sense, from the habitual beliefs of his age or his nation, and from convictions which have grown up in his mind without the cooperation or consent of his deliberate reason. To such a man the world tends to become definite, finite, obvious; common objects rouse no questions, and unfamiliar possibilities are contemptuously rejected (Ibid.: 109-110).

So, he is of the opinion that philosophical reflection crucially differs from everyday thinking. Namely, philosophy is due to change the habitual, ordinary attitude towards the world which is, supposedly, marked by presuppositions, biases, customs, ideologies, etc. Whether or not this claim is empirically confirmed (when articulated as a testable hypothesis, it can be taken on by members of the Xphi camp), the crucial conceptual point is this: There is a distinction, also drawn by Husserl and Carnap, as we shall see later on, between a natural attitude towards the world and towards thinking, and a specifically philosophical attitude. I keep it open at this point what these two conceptually distinguished attitudes actually stand for. Nonetheless, let us provisionally assume that some distinction of this kind is the case. Now, the next question is this: What is, say, the "machinery" - conceptual, logical, or intellectual in the broadest sense - that is responsible for one's change of attitudes?

Russell is explicit about one thing. Namely, he says that there is no special intellectual faculty that is specific to philosophy; hence no philosophical intuition proper, too:

Philosophical knowledge (...) does not differ essentially from scientific knowledge; there is no special source of wisdom which is open to philosophy but not to 
science, and the results obtained by philosophy are not radically different from those obtained from science. (Ibid.: 105).

If this is the case, however, how can we account for the link, explicitly mentioned by Russell, between "the most everyday things" on the one side, and the "possibilities which enlarge our thought" on the other? Is the step from the former to the latter just another exercise of our usual intellectual faculties? Here is the fragment where the two mentioned notions are brought in:

As soon as we begin to philosophise, (...) we find (...) that even the most everyday things lead to problems to which only very incomplete answers can be given. Philosophy, though unable to tell us with certainly what is the true answer to the doubts which it raises, is able to suggest many possibilities which enlarge our thoughts and free them from the tyranny of custom. Thus, while diminishing our feeling of certainty as to what things are, it greatly increases our knowledge as to what they may be; it removes the somewhat arrogant dogmatism of those who have never travelled into the region of liberating doubt, and it keeps alive our sense of wonder by showing familiar things in an unfamiliar aspects (Ibid.: 110).

What is the mechanism responsible for "diminishing our feeling of certainty as to what things are;" for the "knowledge as to what they may be," thus for the move from "the most everyday things" to the realm of possible worlds? How does it happen that the "familiar things" uncover their "unfamiliar aspects"? How does philosophy manage to do all these things? Russell answers these concerns by saying this:

The essential character of philosophy, which makes it a study distinct from science, is criticism. It examines critically the principles employed in science and in daily life; it searches out any inconsistencies there may be in these principles (...) (Ibid.: 105).

I argue that this is not a satisfactory answer. Criticism is also part of everyday thinking; there is no a priori reason to assume that philosophers are more critical than others. Empirical findings show them as equally biased as anybody else (e.g. Buckwalter and Stich 2014; Schwitzgabel and Cushman 2015). So, perhaps the point is not in the scope or intensity of criticism, but in the philosophical criticism's unique approach towards various everyday things. A similar remark pertains to Russell's idea of tracing and eliminating inconsistencies. Which ones, exactly? Our everyday thinking is likely full of inconsistent views, but is philosophy supposed to elicit all of them, or just those philosophically significant? Yet, how are those philosophically significant differentiated from those significant in other fields of inquiry or in everyday life? The answer I wish to flag in this paper can actually be read from Russell's deliberation and his overall standpoint (as we shall see later on), yet it is not articulated explicitly there.

Therefore, I move on now to provide a working characterization of the contents attributable to philosophy. Interestingly enough, their specificity has been acknowledged most acutely by those who carried on with Russell's criticism of the "metaphysicians" and came up with even more far-reaching claims with respect to the very stance of philosophy. In this group Rudolf Carnap and Ludwig Wittgenstein made 
likely the most explicit suggestions that philosophical contents could not be products of ordinary processes of perception, categorization or reasoning. This is because, in their view, apprehending the world the way philosophy does is not just another step within the hierarchy of generality, but a major transcendence of conceptual schemata based on ordinary natural-generic concepts (see Kołodziejczyk 2006; Werner 2017), and a movement either towards nonsensical pseudo-problems (as Carnap, and in some other way Wittgenstein, too, claimed) or towards something more fundamental which underlines the empirical domain as well as the pursuit of science (for the lack of a better word, call this latter group defenders; e.g., Husserl).

It can therefore be presumed that some emergent intellectual faculty is being erected over the sensory and conceptual powers, which makes possible the attempt to transcend natural-generic generality. Now, this can be a genuine faculty (according to the defenders) or some flawed byproduct of our genuine faculties (according to the critics), nonetheless the idea shared by both sides is that the specificity of philosophizing thought of as a generator of content stands out and calls for an explanation.

Here is a possible explanation. Carnap's (1950) distinction between internal question and external questions addresses the specificity in question directly. First he introduced the notion of linguistic framework which is more or less the same as the earlier idea of conceptual apparatus set forth by Kazimierz Ajdukiewicz (1934). This is, roughly, a set of "ways of speaking," thus expressions attributed with reference and strict rules which decide which expressions are formally correct. Now, in addition to propositions within every linguistic framework there are also questions. Carnap especially targets "questions of existence" in his analysis, but the idea at stake could be generalized.

Now, he starts from considering the usual "thing language" in which we can sensibly form questions such as "is there a book on my desk?" or "are unicorns real or imaginary?" which "are to be answered by empirical investigations. Results of observations are evaluated according to certain rules as confirming or disconfirming evidence for possible answers" (Carnap 1950: 21). Then he adds:

The concept of reality occurring in these internal questions is an empirical scientific non-metaphysical concept. To recognize something as a real thing or event means to succeed in incorporating it into the system of things at a particular space-time position so that it fits together with the other things as real, according to the rules of the framework (Ibid.: 22).

So, being an internal question means being internal to the fixed linguistic framework. In this group we find the questions formulated by ordinary people as well as scientists, aside from technicalities introduced by the latter. Now, Carnap says:

From these questions we must distinguish the external question of the reality of the thing world itself. In contrast to the former questions, this question is raised neither by the man in the street nor by scientists, but only by philosophers. Realists give an affirmative answer, subjective idealists a negative one, and the controversy goes on for centuries without ever being solved. And it cannot be solved because it is framed in a wrong way. To be real in the scientific sense means to be an element of the system; hence this concept cannot be meaningfully applied to the system itself (Ibid.). 
Carnap's distinction is not unproblematic for various reasons. Elsewhere (Werner 2017) I discuss it in greater detail, in part following Putnam (2008). Nonetheless, what is critical from the standpoint of this investigation is that Carnap, unlike Russell, seems to suggest that there is a philosophy-specific intellectual faculty of questioning, so to speak, whose allegedly failed character is one thing - one that does not concern us here - but whose distinctness also stands out. Let me put it this way: independently of whether or not we agree with Carnap, there must be, I assume, a fundamental difference between the act of questioning generating internal questions and the act of questioning generating external questions. So, we have two kinds of question-, and more generally, content-generators. I shall follow the latter idea.

\section{The First Posit: Erotetic Intuition}

So, whether or not one agrees with Carnap, it should be clear thanks to his remarks that asking external questions fundamentally differs from asking internal ones, and that the former is the core of philosophizing. But even if one does not accept Carnap's distinction, there still is a take: philosophy starts with some specific acts of questioning.

Wittgenstein also emphasize this fact in his blistering criticism of philosophy:

6.5For an answer which cannot be expressed the question too cannot be expressed

The riddle does not exist.

If a question can be put at all, then it can also be answered.

6.51Scepticism is not irrefutable, but palpably senseless, if it would doubt where a question cannot be asked

For doubt can only exist where there is a question; a question only where there is an answer, and this only where something can be said. (Wittgenstein 1922/1999: 107).

Aside from the fact that in Wittgenstein's view there is no such thing as a plausible philosophical question, we can read from his criticism that if philosophizing were a meaningful intellectual pursuit, it would have been driven by questions or acts of questioning. For Wittgenstein's claim can be read as follows: there is no meaningful philosophical thesis since it is impossible to formulate a meaningful philosophical question. So, his reference to skepticism and doubt can be generalized to the effect that we obtain: a philosophical position can only exist where there is a philosophical question.

Against Carnap and Wittgenstein I provisionally assume, for the sake of this paper, that there are at least some plausible philosophical (external) questions. Otherwise this investigations into the nature of philosophical intuition would be in principle in vein.

So, asking questions stands out as a crucial thing, which can hardly be deemed controversial. However, those participating in the debate on the status of philosophical intuition often seem to forget about it. They seem to forget about this specific kind of cognitive activity which can most simply be described as the formulation of a problem. They seem to suggest that a philosophical judgment exists somewhere in the human mind or emerges there without having been triggered by anything, so to speak. It is then 
assumed that these beliefs are buried somewhere in the mind, ready-made like seed in a fruit. This, however, is a highly controversial assumption whose problematic character is apparent when we look at it in the light brought in by Carnap or Wittgenstein: whether the philosophical beliefs are a serious misstep (as they argued) or a virtue (as a defender would argue), one thing is clear - they are not elements of our ordinary intellectual toolbox.

Let me emphasize this point again: If philosophizing is a product of the state of being misled by the use of language, then there is no such thing as a philosophical belief buried in the mind; instead - the belief must result from a specific exercise of our intellectual capacities, which can hardly be done by accident. Now, we can disagree with Carnap's or Wittgenstein's criticisms of philosophical questions, but the point that was brought to light thanks to them is that, firstly, philosophy starts from specific acts of questioning, plausibly or not; and, secondly, that these specific questions are not products of our usual exercise of concepts and reasoning. Hence, whether the external questions are plausible or implausible, they are external and, therefore, fundamentally differ from the internal questions tackled by an average rational man as well as by scientists. And this difference, putting aside the question of plausibility, is what concerns us here.

To illustrate the point, consider some examples from metaphysics, criticized so much by Russell, Carnap, or Wittgenstein. Think of Thomas Aquinas's deduction of transcendentals by way of analogical reasoning or Spinoza's more geometrico argumentation. Recall Leibniz' system of monadology. It seems completely pointless to conduct a survey on these matters among ordinary language users, not because their judgments on these matters are amateur, as the expertise defense seems to suggest, but because the above-mentioned problems do not arise within the natural, internal or, say, intra-empirical attitude towards the world. These judgments would not, therefore, be amateur; rather, we should say that common judgments on these matters simply do not exist unless the appropriate problems or questions have been raised beforehand.

It is worth noting, however, that also in those philosophical parties that wanted to remain within everyday language, abandon any ambitions of (re)construction, and limit itself to a descriptive role, which includes some members of the analytic movement, the relevant philosophical issues had to be properly brought to light, too. Peter Strawson writes that "just as the grammarian (...) labours to produce a systematic account of the structure of rules which we effortlessly observe in speaking grammatically, so the philosopher labours to produce a systematic account of the general conceptual structure of which our daily practice shows us to have a tacit and unconscious mastery" (Strawson 1992: 7).

While the analogy between the philosopher and the grammarian is fitting, just as a judgment belongs to grammar so long as it is an answer to a specific problem or question concerning the rules of generating expressions in natural language, a judgment also belongs to philosophy, according to Strawson, so long as it is an answer to a question concerning the conceptual apparatus used in everyday language or in science.

The above overview of the issue goes hand in hand with the idea that one manner of differentiating the sciences is by identifying their characteristic questions. Henryk Hiż's proposal is classic when it comes to this issue. He writes: 
Knowledge can be classified according to what questions it answers. Such a classification will give overlapping classes of sentences, where some classes contain more and more varied sentences than other classes, according to the generality of the questions. That scientific knowledge is systematic may be viewed as a result of systematically arranged answers to systematically arranged questions (Hiż 1962: 253).

Regardless of the status of philosophy as a science, it seems that we can risk the following statement, already announced in relation to Wittgenstein's view; namely, $a$ given judgment belongs to philosophy as long as it answers a relevant philosophical question. We shall see that this bond between questions and answers is crucial. If you take, say, my belief that the tree I see in front of my house is real, it is a philosophical belief if its full content can be unpacked, e.g., as "this is a real tree, not a composition of sense-data," but it has nothing to do with philosophy if what I mean is, e.g., "this is a real tree, not a decoration left by the filmmakers whom I leased my backyard yesterday."

Therefore, I propose that philosophical intuition can also manifest itself in the form of a question. This is neither a perceptualist nor doxastic, but an erotetic understanding of philosophical intuition. In short, I set forth the idea of erotetic intuition. Provisionally speaking, this is the capacity of formulating specific questions and as such it may be part of many disciplines; here I am concerned with the capacity of formulating external questions in Carnap's sense of the term, or something similar, thus questions that transcend the boundaries of any domain-specific conceptual framework. These questions include, among others, such as what is real?; what does it mean to know anything?; what is justice?; what is truth?; are properties universals or concretes?; how many kinds of being there are?, etc. So, in other words, this is the capacity to see familiar things in their unfamiliar aspect, as Russell put it. However, this characterization is not complete yet.

One thing may seem clear in light of the above remarks: manifestation in the form of a question precedes manifestation in the form of a judgment or proposition, insofar as the proposition is an answer to the question. The order rolled out may seem convincing but it turns out that this is not the only possible scenario. For, in the first place, it is standard practice in the logic of questions (erotetic logic) to assume that a question is generated by a set of judgments (see Wiśniewski 1995). So, one can hardly understand a given question without tacitly assuming or explicitly providing the proper context or, say, the environment in which the question emerges. And this "environment" consists of propositions; among them be also some possible answers to the question.

As for the latter remarks, Hiż comes up with the idea that questions should be treated as part of larger structures - pairs consisting of a question and an answer. Hiż says that both questions and answers are incomplete or even incomprehensible without their counterpart. Firstly, while an answer "is supposed to be an indicative sentence that makes a statement" (Hiż 1978: 213), the fact is that "answers when separated from the preceding questions are often far from that ideal" (Ibid.). This means that there are answers that are hardly understandable if one does not know the question. Hiz discusses an example from everyday speech; the question "who planned the menu" may be answered by "Felice planned the menu" but also by "Fielice did" or simply "Felice." Now, take any of these answers in disregard of the proper question. "Felice 
did," not to mention "Felice" are hardly informative at all, but also the first answer is ambiguous. For it may be an answer not only to "Who planned the menu?" but also to "What did Felice planned?" or "How did Felice contribute to the party?"

Hence Hiż proposes examining questions and answers as pairs co-occurring within a sentence:

It is therefore natural to treat a question as a part of a longer utterance composed of the question followed by an answer. Questions are incomplete sentences, and so are answers very often. (...)

Among the advantages of thinking of a question as a part of a question-answer sentence is that answers are often not autonomous sentences either. Moreover, short answers are often more natural than complete, full answers. A grammar should give a description of short answers (...) and this seems to be hard to accomplish without taking the question-answer sequence as a unit. (Hiż 1978: 213-214).

Hiż speaks of (in)completeness and autonomy of sentences in the grammatical sense, so the idea of applying his notion of question-answer sentences within the metaphilosophical perspective would require separate extensive studies. Nevertheless, here I would at least like to point to an interesting approach to philosophical judgments, according to which they are in principle (even if they are not articulated in this manner) always a component of a question-answer pair. I unpack this idea in greater detail in the next section.

So, erotetic intuition is thought of here a specific intellectual faculty combining questions and answers; the capacity of making use of what one already knows to call for a new piece of knowledge. Yet, since being "noninferential" is regarded as a birthmark of any intuitive faculty, this must also apply to questions and answers: erotetic intuition can therefore be figuratively characterize as the capacity to "see" problems and puzzles in a given domain even when there is no clear-cut logical sequence of steps producing them.

When it comes to the issue of philosophical intuition, I suggest at this point, that since the system of questions and answers (propositions, theses, judgments), including also specific experiences, is so complex, it cannot be reduced to the claim that philosophers simply devote more time and attention to their intuitions, which, at their core, are the same as everyone else's, the only differentiating factor being the amount of time. The real differentiating factor turns out to be the unique generator of philosophical content, i.e. the whole complex machinery of questions, answers, and experiences. Hence, the difference must be in the philosophers' use of their erotetic intuition. Arguably, the term "philosophical intuition" stands for this whole machinery, not a single unrelated act of believing.

\section{The Banality of Philosophical Questions (and Beliefs)}

One thing is whether or not philosophical intuition produces nonsensical utterances, and another puzzle is whether it can produce valuable or insightful utterances; that is to say, questions and answers that draw our attention to something new, interesting, 
challenging, etc. As mentioned, I assume that external questions, including metaphysical questions, do make sense. At the same time I wish to raise the issue of their apparent banality.

This is an extremely subtle and key issue. The controversy surrounding philosophical intuition should turn our attention to the fact that philosophical content is not generated using some peculiar technical language, but - as I will argue - through a specific attitude towards the world as experienced, thus the empirical domain as such, which nevertheless uses the expressive devices of natural language. Of course, philosophical language has established its own technicalities, but as a rule, philosophical content can be successfully articulated using common expressions. The price to be paid is the apparent banality of all and any attempts to express philosophical content (see Kołodziejczyk 2017).

I am talking about the banality manifesting itself when one looks at philosophical problems and claims simply as ordinary expressions in natural language. In other words, wishing to understand the ultimate problems pertaining to the world as we experience it, these claims appear banal or trivial when one looks at them from within the everyday experience and from within the conceptual frameworks designed to capture this experience; in other words - philosophical questions may appear trivial if one looks at them as if they were internal questions (the same applies to philosophical beliefs). Thus, if we adopt the evaluation criteria applied to non-philosophical intellectual efforts directed at a given fragment or aspect of the world, then the outcomes of philosophical efforts seem not to alter anything; i.e. not to provide any new knowledge.

Let us consider an example. In her introduction to philosophy Maralee Harrell writes:

Many Introduction to Philosophy textbooks begin with an admonition that people generally don't understand what philosophy is. I don't find this to be the case, though. On the first day of class, I always ask my students to think of questions that they think are paticularly philosophical; and they always do a great job (...). Usually the list goes something like this:

Does God exist?

What is human nature?

What can we know?

(...)

What is real?

What is consciousness?

Is truth relative? (Harrell 2016: 3-4; see e.g. Horner and Westacott 2000 in the same spirit).

Let us note, however, that nothing a priori makes the question "What is real?" a philosophical one, while on the level of common interpretation the answer to it may be trivial: the table at which I am sitting is real, while the dinosaur I see when wearing a virtual reality headset is not. If the philosopher interprets the same question differently, for example in the context of the realism vs. idealism dispute about the existence of the world, then the conclusion is that there must be an additional factor which, so to speak, de-banalizes the question. The same goes for the question regarding the relativity of truth, or, more generally, the nature of true propositions (judgments). The answer to the question of what it means for the proposition "Snow is white" to be true is seemingly 
trivial for anyone who has ever seen snow, while the issue of the relativity of truth is immediately resolved by anyone who can see the difference between the propositions " $2+3=5$ " and "Krystian Zimerman is a better Chopin player than Maurizio Pollini." Indeed, there are relative truths, although not all truths are relative (ergo: what is there to "philosophize" about?). Moreover, even if the question is not apparently trivial, it is by no means obvious that it is philosophical. The question of God is philosophical if "God" refers for example to the specific being that Anselm of Canterbury had in mind in his ontological proof, but a Christian or Jewish theologian likely understands this utterance differently. The same applies to the question of consciousness and how the latter is operationalized in cognitive science.

To take a different example, note that some of the most puzzling points made by Wittgenstein in his Tractatus are apparent trivialities:

5.621 The world and life are one.

5.63 I am my world. (The microcosm.) (Wittgenstein 1922/1999: 89).

Yet, we suspect that there is something laid down in these claims, that renders them non-trivial. So, putting together all the things discussed so far we must seek to understand the nature of this "de-banalizing" factor (if any), which must partake in the machinery of erotetic intuition used by philosophers, so that it can legitimize philosophy as an intellectual effort.

\section{The Idea of a Radical Starting Point}

Seeking a de-banalizing factor, I believe it is worthwhile to look at philosophical schools which did not consider the question of reality, truth or similar concerns as the most fundamental questions, philosophically speaking, but demanded going even further, digging down to a level of reflection where thought could gain a neutral footing. Only then, according to this approach, all those further puzzles can be taken on, including the question about reality, mind-dependence, truth, knowledge, etc. So, I will be offering a working reflection, following Edmund Husserl (1950/1982), on the philosophies of the radical starting point or radical beginning.

The idea of a radical starting point comes from Descartes, and in the twentieth century it was explicitly formulated by Husserl, who consciously referred to the author of the Meditations on First Philosophy. Husserl emphasizes that the quest for a radical starting point is individual; it begins with a specific kind of self-knowledge, when I myself become the center or point of reference in relation to which all the manifest and scientific images of the world, as Sellars (1956) would put it, are to be situated. In Cartesian Meditations we read:

First, anyone who seriously intends to become a philosopher must "once in his life" withdraw into himself and attempt, within himself, to overthrow and build anew all the sciences that, up to then, he has been accepting. Philosophy (...) is the philosophizer's quite personal affair. It must arise as his wisdom, as his selfacquired knowledge tending toward universality, a knowledge for which he can answer from the beginning, and at each step, by virtue of his own absolute 
insights. If I have decided to live with this as my aim the decision that alone can start me on the course of a philosophical development I have thereby chosen to begin in absolute poverty, with an absolute lack of knowledge. (Husserl 1950/ 1982: 2).

In Husserl's opinion, this step towards radical self-knowledge is linked to a certain attitude towards the world which is not possible in everyday, ordinary approaches characterized as the natural attitude. In Ideas I we read:

By my seeing, touching, hearing, and so forth, and in the different modes of sensuous perception, corporeal physical things with some spatial distribution or other are simply there for me, "on hand" in the literal or the figurative sense, whether or not I am particularly heedful of them and busied with them in my considering, thinking, feeling, or willing (Husserl 1913/1983: 51).

Earlier in this book Husserl writes:

Natural cognition begins with experiences and remains within experience. In the theoretical attitude which we call the "natural" $<$ theoretical attitude $>$ the collective horizon of possible investigations is therefore designated with one word: It is the world. Accordingly, the sciences of this original attitude are, in their entirety, sciences of the world (...). (Ibid.: 5).

The key, therefore, is not so much that the existence of the world is naturally assumed, not to mentioned being deliberately endorsed as part of the natural attitude; rather, in the natural attitude the very presence of the world as it is experienced appears as something so obvious (it is "at hand") as not to inspire reflection at all - it is not problematized in thinking. The world is just there, present to me.

Bracketing the natural attitude, postulated by Husserl - the epoché - is therefore a condition which makes the said problematization possible, even before any further reflective steps have been taken.

Instead of remaining in this [natural] attitude, we propose to alter it radically (Ibid.: 57).

We put out of action the general positing which belongs to the essence of the natural attitude; we parenthesize everything which that positing encompasses with respect to being: thus the whole natural world which is continually "there for us", "on hand," and which will always remain there according to consciousness as an "actuality" even if we choose to parenthesize it.

If I do that, as I can with complete freedom, then I am not negating this "world" as thought I were a sophist; I am not doubting its factual being as though I were a skeptic; rather I am experiencing the "phenomenological" غ̇ं⿰охท which also completely shuts me off from any judgmennt about spatiotemporal factual being (Ibid.: 61).

The crucial thing is this: if the epoché is neither negating nor doubting the experienced world, it is all about taking the world solely as it manifests itself - taking it in its relation 
to the subject, thus qua experienced, yet without making it subordinate to the subject (which is a metaphysical claim, bracketed alongside all other metaphysical claims).

Dan Zahavi comments on that specific standpoint in the following words, pointing out that for Husserl exercising the epoché is critical for philosophizing as such, not just for his own philosophical project:

The epoche is the term for our abrupt suspension of a naive metaphysical attitude, and it can consequently be likened to a philosophical gate of entry (...).

To perform the epoche and the reduction is not to abstain from an investigation of the real world in order to focus on mental content and representations, as it has occasionally been claimed (...). The epoche and the reduction do not involve an exclusive turn toward inwardness, and they do not imply any loss. On the contrary, the fundamental change of attitude makes possible a decisive discovery and should consequently be understood as an expansion of our field of research (...). Suddenly, the perpetually functioning, but so far hidden, transcendental subjectivity is disclosed as the subjective condition of possibility for manifestation (Zahavi 2003: 46; my emphasis).

Interestingly, the idea of anchoring science in what is given as given was also the premise of Carnap's (1928) Aufbau project, i.e., the idea of creating a coherent system of concepts (a constitutive system, as Carnap called it) founded on basic notions, which would then be harnessed within a suitable logical machinery to enable the unity of the sciences, i.e., a single coherent scientific image of the world. This can be seen most clearly when Carnap selects the most appropriate base for his system. He finds it in subjective experiences taken not as the creations of an actual psychophysical subject, but as neutral atoms of cognition: they are to serve as given, and not a result of some kind of relationship to a supposed reality. In fact, Carnap directly references an analogous effort by Husserl. We can read:

The autopsychological basis is also called solipsistic. We do not thereby subscribe to the solipsistic view that only one subject and its experiences are real, while the other subject are nonreal. The differentiation between real and nonreal objects does not stand at the beginning of the constructional system. As far as the basis is concerned, we do not make a distinction between experiences which subsequent constructions allow us to differentiate into perceptions, hallucinations, dreams, etc. This differentiation and thus the distinction between real and nonreal objects occurs only at a relatively advanced constructional level (...). At the beginning of the system, the experiences must simply be taken as they occur. We shall not claim reality or nonreality in connection with these experiences; rather, there claims will be "bracketed" (i.e., we will exercise the phenomenological "with-

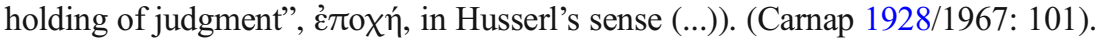

Yet, it should be clear that this specific neutrality obtained by the exercise of "bracketing" cannot be part of the natural attitude. A major reason for that is the fact that in Carnap's approach the giveness "does not presuppose somebody or something to whom the given is given (...).” (Ibid.: 102). Further on we read: 
The expressions 'autopsychological basis' and 'methodological solipsism' are not to be interpreted as if we wanted to separate, to begin with, the "ipse", or the "self", from the other subjects, or as if we wanted to single out one of the empirical subjects and declare it to be the epistemological subject. At the outset [i.e., at the base level of the reduction], we can speak neither of other subjects nor of the self. Both of them are constructed simultaneously at a higher level (...) (Ibid.: 103-104).

When it comes to the everyday view of the world, however, it is difficult to imagine grasping what is given only within the bounds of this "givenness," so to speak. The natural attitude, as Husserl called it, is determined, inter alia, by the distinction between subject and object, while the radical starting point, as Carnap aptly put it, should lie one step ahead of this distinction. Egocentricity, as the author of The Logical Structure of the World calls it, and so the reference to the subject as the opposite of the alleged object, is a type of construct, not something given.

Now, I am not ruling whether the search for a radical starting point in philosophy can be successful (whatever being successful means in this context). I only claim that there is a take from the fact that such an attempt is at the heart of so otherwise different systems as the ones developed by Husserl and Carnap.

First of all, in addition to the fact that philosophical claims are closely correlated with appropriate questions, which was elicited in the previous section, it is now also apparent that these questions have to result from a very peculiar change of attitude. In short: it is virtually impossible to produce a philosophical problem, at least from the perspective shared by Husserl and Carnap, without abandoning the natural attitude. This metaphilosophical position casts doubt on the procedure of questioning nonphilosophers about philosophical matters without learning them how to exercise bracketing or something similar (which is, in principle, a thinkable scenario provided that Xphi enriches its methods; see Andow 2016). As announced, the problem with this procedure is not that people give amateur answers; the real issue is that they give answers to different questions.

Secondly, if the idea of radical beginning is at the heart of so otherwise different systems as the ones developed by Husserl and Carnap, it is possible that bracketing exercised by both thinkers is an instantiation of a more general intellectual pursuit standing in the heart of philosophizing as such; or that the bracketing originates from an intellectual effort shared by, ceteris paribus, all philosophers. I shall risk a hypothesis that the latter is true. The common intellectual source of philosophizing, I argue, is what I dubbed recognition of one's epistemic position. And this specific intellectual act is, I argue, the sought de-banalizing factor which renders the mentioned seemingly trivial questions non-trivial.

To be more precise, I argue that philosophical intuition is the capacity to recognize the epistemic position.

\section{The Second Posit: Recognizing one's Epistemic Position}

The search for a radical starting point prior to making any distinction between the real and the unreal, between subject and object, cannot take place within the natural attitude. 
What we need is a radical change of attitude and an attempt to transcend (in thought) the boundaries of our everyday experience of the world. This should be a special act of the intellect, enabling the emergence of philosophical content. I shall make the case that this change of attitude originates from a specific recognition.

Epistemic position: in short (for more details see Werner 2916), being in a specific epistemic position is, first, having a certain location in the world, which imposes a perspective; and second, being equipped with specific sensory and mental cognitive tools. It is here that we find different kinds of senses with their proper nature and sensitivity, as well as systems of categories and concepts ordering the data of experience, and finally logic, understood as a method for drawing conclusions from the data obtained. Thirdly, one can claim that the emergent product of the above-mentioned factors is the circumstance which Crane (2001), already cited, aptly described as the fact that every minded creature is not only in the world, but also that the world is a certain way for each minded creature. Every subject has or is a unique point of reference for the entire universe of things, facts, and processes - everything that happens around it. There is a stone in the world, but there is no point in saying that the world is a certain way for the stone, while the same statement makes sense, Crane argues, for every minded creature (let us add that this is not necessarily limited to humans). In the same spirit, Wittgenstein says in the first proposition of the Tractatus that "The world is all that is the case," and a bit further on he adds "The world is my world." What happens (what is the case) happens to me. Otherwise, as Wittgenstein seems to be saying, the category of the world makes no sense whatsoever.

Recognition: Recognizing my epistemic position is my becoming aware of the facts described above. It is therefore about me recognizing everything that happens ("is the case") precisely as that which happens around me, and is somehow tailored to my cognitive measure. It is about pointing out that the whole world as it appears to me, the world qua experienced, is a phenomenon, and thus a certain presentation.

The philosophy of cognitive science, drawing on the achievements of theoretical biology, provides a promising conceptual framework for exploring the issue we are interested in. This framework is the classic concept of Umwelt introduced a hundred years ago by Jacob von Uexküll (1926). Every organism lives in a kind of information cocoon determined by its cognitive tools, life needs, and capabilities. For example, the Umwelt of the tick analyzed by Uexküll is essentially limited to a single type of stimulus, namely butyric acid, which the tick is able to detect in its environment, and to two types of actions: the tick climbs a plant and drops down when the concentration of butyric acid ("signaling" the approach of an animal, a potential host) triggers this response. Of course, the Umwelt of higher-order animals, not to mention humans, is immensely richer, but in principle, like the tick, we are always dealing with a made-to-measure, and therefore necessarily limited view of reality, and not, to put it in Kantian terms, with things in themselves. More recent literature describes this "fact" as every cognitive entity shaping or "enacting" (see Varela et al. 1991) its cognitive niche (see Tooby and DeVore 1987; Pinker 2010; Bertolotti and Magnani 2017; Werner 2018).

Recognizing my epistemic position means becoming aware of the fact that my world is my Umwelt, or cognitive niche; i.e., something tailored to my cognitive measure. To put it simply using classical vocabulary: it is the recognition that reality is always given 
to me in the form of a certain phenomenon and as such, it could be different. Wittgenstein puts is explicitly:

\section{$5.634(.$.}

Everything we see could also be otherwise.

Everything we can describe at all could also be otherwise.

There is no order of things a priori. (Wittgenstein 1922/1999: 90).

Partial recognitions of this type sometimes occur in everyday life, when, for example, we discover that our senses sometimes deceive us. Cognitive psychology, which examines the contextual dependence of perception, conceptualization, memory, etc., also provides relevant examples. However, a special characteristic of the recognition of one's epistemic position, as understood here, is its holistic and radical character, i.e., the whole empirical domain is apprehended as that which appears - as given in Carnap's sense. It is therefore easy to counter faulty perceptions of shapes under certain circumstances or erroneous categorization within a certain context with adequate perception and adequate categorization in standard conditions, yet we don't have access to anything with which the empirical domain as a whole could be compared. This wholeness, then, is something specific which seems to require more than just the summation of specific cases; namely, a qualitatively new step, resulting from a kind of special reflection or meditation of the kind carried out by Descartes, Husserl, Wittgenstein or Carnap.

To substantiate the latter point, let me go back to Russell. He starts from carefully analyzing each sense as to what kind of data it delivers, how different these data may be depending on context and perspective, and based on that he draws a general conclusion:

For most practical purposes these differences are unimportant, but to the painter they are all-important: the painter has to unlearn the habit of thinking that things seem to have the colour which common sense says they "really" have, and to learn the habit of seeing things as they appear. Here we have the beginning of one of the distinctions that cause most trouble in philosophy - the distinction between "appearance" and "reality," between what things seem to be and what they are (Russell 1912/2004: 2).

Most interestingly, Russell is perfectly clear that one can actually recognize the appearance vs. reality diction only as the result of a specific general change of attitude. Otherwise, thus if one does not abandon the habitual way of seeing everyday things the natural attitude, as called by Husserl - one is in principle unable to see the difference at stake. So, distinguishing appearances from reality is the immediate consequence of seeing the world anew - qua experienced, that is to say, as a particular presentation fitting one's cognitive measure. In this context Russell emphasizes the analogy between philosophers and painters: you cannot be a painter without changing your way of perceiving the world, independently of how skilled you are, Russell seems to claim, and you cannot become a philosopher, too, without the analogous change in the way you approach your surroundings - again, independently of how excellent your academic training was.

So, recognizing one's epistemic positions opens up the prospect of a new kind of generality - a generality which isn't only the result of adding up local 
similarities and differences between perceptions, features, or phenomena, but one that allows the whole of the world qua experienced to be grasped in a single act of the intellect. If we approach this act from the perspective of Chudnoff's (2011) perceptualist account of intuition, it is clear that we don't have to do with a belief of any kind, but certainly some content is just presented to the subject to the effect that the subject can actually "see" or experience the world and herself in the world anew in spite of the fact that, "objectively" speaking, nothing changes.

So, the recognition of one's epistemic position could be considered as an experience of some specific sort. It's just like in later Wittgenstein's aspectual seeing:

The expression of a change of aspect is the expression of a new perception and at the same time of the perception's being unchanged. (Wittgenstein 1953: 196).

When I recognize a rabbit in the famous duck-rabbit illustration, "objectively" nothing is changed in the world, yet the whole world is different to me; from now on it is $a$ world with a rabbit.

The recognition of one's epistemic position is thus like aspectual seeing: it enables one to see the whole world under a new aspect. As such, it puts the whole world in a new frame, so to speak, while at the same time it may seem that nothing changes. It's just like changing "the limits" of the world, not the world itself, articulated in the following fragment from Wittgenstein's Tractatus:

6.43 If good or bad willing changes the world, it can only change the limits of the world, not the facts; not the things that can be expressed in language

In brief, the world must thereby become quite another. It must so to speak wax or wane as a whole.

The world of the happy is quite another than that of the unhappy. (Wittgenstein 1922/1999: 106).

From this angle we can also read the following words:

6.44 Not how the world is, is the mystical, but that it is.

6.45 The contemplation of the world sub specie aeterni is its contemplation as a limited whole.

The feeling of the world as a limited whole is the mystical feeling. (Ibid.: 107).

Arguably, this is the reason behind the apparent triviality or banality of philosophical questions and answers. Namely, they seem such when they are supposed to refer to some facts; meanwhile they refer to what Wittgenstein refers to as "the limit" of the domain of facts. As in aspectual seeing, "philosophical seeing," if I can put it this way, changes nothing in particular, yet it renders the whole world different.

In my view, this act of going beyond local generality towards the "limits" and the "feeling of the world a limited whole" has to be connected with a specific act of selfknowledge: presentation of oneself as the one to whom the world as a whole appears and, at the same time, presentation of the world as that which appears. Wittgenstein puts it aptly: 
$5.62(.$.

In fact what solipsism means, is quite correct, only it cannot be said, but it shows itself.

That the world is my world, shows itself in the fact that the limits of the language (the language which only I understand) mean the limits of my world. (Ibid.: 89).

(...)

5.641 There is therefore really a sense in which in philosophy we can talk of a non-psychological I. The I occurs in philosophy through the fact that the "world is my world"

The philosophical I is not the man, not the human body or the human soul of which psychology treats, but the metaphysical subject, the limit—not a part of the world. (Ibid.: 90).

In this light the already cited "trivialities" become expressions of a philosophical thought:

5.621 The world and life are one.

5.63 I am my world. (The microcosm.) (Ibid.: 89).

Therefore, the sought de-banalizing factor is the specific act, and at the same time the specific experience of recognizing oneself as "the limit - not a part of the world" and the world as "my world."

Finally, I propose a view according to which, in short, philosophical intuition is the capacity of recognizing one's epistemic position. To be more precise, philosophical intuition can be described as the exercise of erotetic intuition, thus the intellectual machinery of questions and answers, driven by the unique experience of the recognition of one's epistemic position. This means that a question is philosophical if it is generated by the recognition of one's epistemic position (admittedly, unlike the relation of generating a question in standard erotetic logic, e.g. one developed by Wiśniewski 1995, the relevant relation pertaining to philosophical questions has not been investigated properly). Finally, a belief is philosophical when it answers a philosophical question (against Wittgenstein who holds that in fact there are no such things as philosophical questions).

After so many quotes and references, the reader must think that the idea proposed here is nothing new. I am not claiming originality, however, and all these extensive quotes I brought up leave no doubt about it. At the heart of the idea I am discussing is something quite to the contrary: my aim is to articulate what has been implicit in a variety of different philosophical views and schools. Mentioning Russell, Husserl, Carnap and Wittgenstein was supposed to substantiate this belief at least in part. Of key importance, in my view, however, is that the notion at stake is not owned by any particular school. The key to a proper understanding of the proposal referenced here is therefore the idea that the category of recognizing one's epistemic position for meta-philosophical purposes should be separated from its entanglement in any particular philosophical system. In other words, it seems that the idea of holistically realizing that we are always 
cognitively dealing with a domain of experience and thought tailored to our cognitive measure, if it ever was explicitly formulated, served an auxiliary function in Descartes, Kant, Husserl, or Carnap - in relation to what followed next, namely the proposal of a specific theory regarding the origins of knowledge, methods, or other issues (in Wittgenstein's case, the situation is a bit different; see Werner 2016). It was therefore a ladder whose purpose was to lead to the proper destination, opening up a field in which a specific philosophical claim could be justified. To put it simply, one can say the following: from the perspective of the goals to be attained by these considerations, the idea of recognizing one's epistemic position is an independent meta-philosophical theoretical postulate, which is to make us aware of the peculiarity of philosophical intuition, and then of philosophical questions and answers.

Let us go back, therefore, and reconsider some of the questions deemed "naturally" philosophical by Harrell (2016), meaning that they are supposed to be philosophical independently of how they are actually generated by the reflecting subject. As I said, there is no reason to assume that the question "What is real?" is philosophical in nature when it occurs in the pair "What is real? - This chair is real and the elephant on the chair is not," when we juxtapose a real chair with a virtual and therefore unreal elephant pattern on it. But seemingly the same (actually, very different) question does have a philosophical character for example in the pair "What is real? - Material objects are real and sense data are not real," when the reality of matter is contrasted, for example, with the proclaimed unreality (i.e., some kind of reducibility) of the content of perception. However, one who articulates the latter must have seen the world in a way that is not possible from within the natural attitude and requires one to problematize e.g. Russell's distinction between the world recognized as a domain appearances and a presumed reality behind them. The same applies to the questions of truth or knowledge. They are not about this or that specific case but, once again, can only be properly (philosophically) understood in the light of the recognition of the appearancereality distinction. The first chapter of Russell's book is precisely about knowledge, yet he is clear about the proper perspective from which he targets this issue:

It has appeared that, if we take any common object of the sort that is supposed to be known by the senses what the senses immediately tell us is not the truth about the object as it is apart from us, but only the truth about certain sense-data which, so far as we can see, depend upon the relations between us and the object (...) But if the reality is not what appears, have we any means of knowing whether there is any reality at all? And if so, have we any means of finding out what it is like? (Russell 1912/2004: 7).

So, the essentially philosophical nature of some questions results from a very specific intellectual (and experiential) "machinery" which generated them. Not everything that sounds philosophical, as it were, is in fact part of philosophy, just like countless utterances of Einstein's equation " $\mathrm{E}=\mathrm{mc}^{2}$ " do not necessarily belong to the proper discourse of physics. This latter issue brings us back to the expertise defense. A brief reconsideration of it will serve as a conclusion of this essay. 


\section{Conclusion: The Expertise Defense Revisited}

I shall now reformulate the expertise defense. An important element of this reformulation is the view that common intuitions and philosophical intuitions do not only differ when it comes to the level of scrutiny or the amount of scholarly knowledge implemented in them; the crucial thing is that in the strict sense of the word these two intuitions do not give rise to comparable products in the form of questions and beliefs. In this sense, for example, an epistemologist dealing with the question about the nature and possibility of knowledge does not have to - and indeed cannot - ask random passers-by about their opinions. It is logically unsound to juxtapose his beliefs with those of non-philosophers due to reasons which I will summarize below. The analogy to a physicist or mathematician sometimes used against Xphi is not accurate for other reasons, but it does highlight the issue of compatibility or comparability of beliefs.

First of all, questions and answers (i.e. the beliefs that answer the questions) constitute pairs, as stressed by Hiż $(1962,1978)$. Each of the elements of such a pair is incomplete without the other. Admittedly, a certain belief may be articulated without its "tail," i.e. the question, nevertheless the "tail" must be taken into account if we want to grasp the full import or content of the said belief. It may be tacitly assumed and agreed upon by the participants of a particular discourse. Therefore, philosophical beliefs in the strict sense of the term are always an element of a question-answer pair, and for this reason it is logically incorrect to separate a particular belief from its philosophical question and to set it side by side with a belief that either does not have its own proper question (likely not all our everyday beliefs answer specific questions) or whose question is of a significantly different type.

What does it mean for questions to be the same or a different type of question? I am not referring to types such as open and closed questions, questions of resolution, and so on. What I mean is a typology of questions depending on the type of act of questioning or intellectual faculty from which the question springs. It is here that my central theoretical posit comes to the fore, i.e., philosophical intuition understood as the capacity to recognize one's epistemic position.

If we concede that a philosophical question is produced by an act of inquiry based on recognizing one's epistemic position, it may be claimed that a philosophical question is of a different type than common or scientific questions. One of the ways in which this difference could be unpacked is to say that while a philosophical question is always external in Carnap's sense, questions posed in everyday life as well as in science are always internal. However, since the recognition is the key differentiating factor, someone could reject Carnap's distinction while still emphasizing the fundamental difference between philosophical and non-philosophical questions.

The corrected version of the expertise defense should go something like this: properly philosophical beliefs stem from exercising philosophical, erotetic intuition understood as the capacity to come up with question-answer pairs (thus the capacity to problematize certain issues) based on the recognition of one's epistemic position. This capacity, in potentia, is most likely inherent in all or most people, but its enactment or exercise is what matters here. Therefore, taking these beliefs in isolation and juxtaposing with beliefs having nothing to do with the 
exercise of philosophical intuition as it is portrayed here, is logically incorrect. For these two sets of beliefs are incomparable even if they appear similar in content, insofar as they belong to different question-answers pairs.

Open Access This article is licensed under a Creative Commons Attribution 4.0 International License, which permits use, sharing, adaptation, distribution and reproduction in any medium or format, as long as you give appropriate credit to the original author(s) and the source, provide a link to the Creative Commons licence, and indicate if changes were made. The images or other third party material in this article are included in the article's Creative Commons licence, unless indicated otherwise in a credit line to the material. If material is not included in the article's Creative Commons licence and your intended use is not permitted by statutory regulation or exceeds the permitted use, you will need to obtain permission directly from the copyright holder. To view a copy of this licence, visit http://creativecommons.org/licenses/by/4.0/.

\section{References}

Ajdukiewicz, K. (1934). Das Weltbild und die Begriffsapparatur. Erkenntnis, 4(1), 259-287.

Alexander, J. (2012). Experimental philosophy: An introduction. Cambridge: Polity.

Andow, J. (2016). Qualitative tools and experimental philosophy. Philosophical Psychology, 29(8), 11291141.

Baz, A. (2017). The crisis of method in contemporary analytic philosophy. Oxford: Oxford University Press.

Beebe, J. R. (2012). Experimental epistemology. In A. Cullison (Ed.), Companion to epistemology (pp. 248269). London: Continuum.

Bertolotti, T., \& Magnani, L. (2017). Theoretical considerations on cognitive niche construction. Synthese, 194, 4757-4779.

Brown, J. (2011). Experimental philosophy, Contextualism and SSI. Philosophy and Phenomenological Research, 86(2), 233-261.

Buckwalter, W. (2010). Knowledge Isn't closed on Saturday: A study in ordinary language. Review of Philosophy and Psychology, 1(3), 279-296.

Buckwalter, W. (2012). Non-traditional factors in judgments about knowledge. Philosophy Compass, 7(4), $278-289$.

Buckwalter, W., \& Schaffer, J. (2015). Knowledge, stakes, and mistakes. Nô̂s, 49(2), 201-234.

Buckwalter, W., Stich, S. (2014). Gender and philosophical intuition, [w:] J. Knobe, S. Nichols (red.), Experimental philosophy, volume 2, Oxford University press: New York, pp. 307-346.

Cappelen, H. (2012). Philosophy without intuitions. Oxford: Oxford University Press.

Carnap, R. (1928). Der Logische Aufbau der Welt. Leipzig: Felix Meiner Verlag. Quotations from: R. Carnap, The Logical Structure of the World. Pseudoproblems in Philosophy. Berkeley \& Los Angeles: University of California Press 1967.

Carnap, R. (1950). Empiricism, semantics, and ontology. Revue Internationale de Philosophie, 4, $20-40$.

Chudnoff, E. (2011). What intuitions are like. Philosophy and Phenomenological Research, LXXXII(3), 625654.

Crane, T. (2001). Elements of mind. Oxford: Oxford University Press.

Dehaene, S. (2009). Origins of mathematical intuition: The case of arithmetic. Annals of the New York Academy of Sciences, 1156, 232-259.

Deutsch, M. (2010). Intuitions, counter-examples, and experimental philosophy. Review of Philosophy and Psychology, 1, 447-460.

Egler, M., \& Ross, L. D. (2018). Philosophical expertise under the microscope. Synthese, preprint, 1-22. https://doi.org/10.1007/s11229-018-1757-0.

Harrell, M. (2016). What is the argument. An introduction to philosophical argument and analysis. Cambridge MA: MIT Press.

Hiż, H. (1962). Questions and answers. Journal of Philosophy, 59(10), 253-265.

Hiż, H. (1978). Difficult questions. In H. Hiż (Ed.), Questions (pp. 211-226). D. Reidel: Dordrech.

Horner, C., \& Westacott, E. (2000). Thinking through philosophy. An introduction. Cambridge: Cambridge University Press.

Husserl, E. (1913). Ideen zu einer reinen Phänomenologie und phänomenologischen Philosophie, I, Buch: Allgemeine Einführung in die reinen Phänomenologie. Halle: Max Niemeyer Verlag. Quotations from: E. 
Husserl, Ideas pertaining to a pure phenomenology and to a phenomenological philosophy. First Book: General introduction to a pure phenomenology. The Hague/Boston/Lancaster: Martinus Nijhoff Publishers/Kluwer 1983.

Husserl, E. (1950). Cartesianische Meditationen. Den Haag: Martinus Nijhoff. Quotations from: E. Husserl, Cartesian Meditations. An Introduction to Phenomenology. The Hague/Boston/London: Martinus Nijhoff Publishers/Kluwer 1982.

Kauppinen, A. (2007). The rise and fall of experimental philosophy. Philosophical Explorations, 10, $95-118$.

Knobe, J. (2003). Intentional action and side effects in ordinary language. Analysis, 63(279), 190-194.

Knobe, J. (2015). Philosophers are doing something different now: Quantitative data. Cognition, 135, 36-38.

Knobe, J., Buckwalter, W., Robbins, R., Sarkissian, H., Sommers, T., \& Nichols, S. (2012). Experimental philosophy. Annual Review of Psychology, 63, 81-99.

Knobe, J., \& Nichols, S. (2008). An experimental philosophy manifesto. In J. Knobe \& S. Nichols (Eds.), Experimental philosophy (pp. 3-16). Oxford: Oxford University Press.

Knobe, J., \& Nichols, S. (2017). Experimental philosophy, [w:] E. Zalta (ed.) Stanford Encyclopedia of Philosophy: URL = https://plato.stanford.edu/archives/win2017/entries/experimental-philosophy/.

Kołodziejczyk, S. T. (2006). Granice pojęciowe metafizyki [The conceptual boundaries of metaphysics], Wrocław: Uniwersytet Wrocławski.

Kołodziejczyk, S. T. (2017). Rola intuicji w poznaniu filozoficznym. Między kontekstem odkrycia a kontekstem uzasadnienia [Intuition in Philosophy. Between the Context of Discovery and the Context of Justification], Kwartalnik Filzoficzny XLV (4), 5-36.

Kuntz, J. R., \& Kuntz, J. R. C. (2011). Surveying philosophers about philosophical intuition. Review of Philosophy and Psychology, 2, 643-665.

Lewis, D. (1983). Philosophical papers: Volume I. New York: Oxford University Press.

Livengood, J., Sytsma, J., Feltz, A., Scheines, R., \& Machery, E. (2010). Philosophical temperament. Philosophical Psychology, 23(3), 313-330.

Ludwig, K. (2007). The epistemology of thought experiments: First person versus third person approaches. Midwest Studies in Philosophy, 31(1), 128-159.

Machery, E. (2011). Thought experiments and philosophical knowledge. Metaphilosophy, 42(3), 191-214.

Machery, E. (2012). Expertise and intuitions about reference. Theoria, 27, 37-54.

Machery, E., Mallon, R., Nichols, S., \& Stich, S. (2004). Semantics, cross-cultural style. Cognition, 92(3), B1B12.

Machery, E., Stich, S., Rose,D., Chatterjee, A., Karasawa, K., Struchiner, N., Sirker, S., Usui, N., Hashimoto, T. (2015). Gettier across cultures, Noûs 51(3), 645-664.

Nadelhoffer, T., \& Nahmias, E. (2007). The past and future of experimental philosophy. Philosophical Explorations, 10(2), 123-149.

Nado, J. (2014). Philosophical expertise. Philosophy Compass, 9, 631-641.

Nado, J. (2016). The intuition deniers. Philosophical Studies, 173(3), 781-800.

Nichols, S., \& Ulatowski, J. (2007). Intuitions and individual differences: The Knobe effect revisited. Mind \& Language, 22(4), 346-365.

Nichols, S., Stich, S., \& Weinberg, J. (2003). Metaskepticism: Meditations in ethno-epistemology. In S. Luper (Ed.), The skeptics (pp. 227-247). Farharn: Ashgate Press.

Paprzycka, K. (2015). The omissions account of the Knobe effect and the asymmetry challenge. Mind \& Language, 30(5), 550-571.

Pinker, S. (2010). The cognitive niche: Coevolution of intelligence, sociality, and language. PNAS, 107(11), 8993-8999.

Prinz, J. J. (2008). Empirical philosophy and experimental philosophy. In J. Knobe \& S. Nichols (Eds.), Experimental philosophy (pp. 189-208). Oxford: Oxford University Press.

Putnam, H. (2008). Wittgenstein and realism. International Journal of Philosophical Studies, 16(1), 3-16.

Rini, R. A. (2015). How not to test for philosophical expertise. Synthese, 192, 431-452.

Roberts, P., Andow, J., \& Schmitdtke, K. A. (2017). Lay intuitions about epistemic normativity. Synthese., 195, 3267-3287. https://doi.org/10.1007/s11229-017-1371-6.

Russell, B. (1912). The Problems of Philosophy. London: Williams and Norgate. Quotations from: B. Russell, The Problems of Philosophy. New York: Barnes \& Noble 2004.

Schwitzgebel, E., \& Cushman, F. (2012). Expertise in moral reasoning? Order effects on moral judgment in professional philosophers and non-philosophers. Mind \& Language, 27, 135-153.

Schwitzgebel, E., \& Cushman, F. (2015). Philosophers' biased judgments persist despite training. Expertise and Reflection, Cognition, 141, 127-137.

Schwitzgebel, E., \& Rust, J. (2009). The moral behaviour of ethicists: Peer opinion. Mind, 118, 1053-1059. 
Sellars, W (1956). Empiricism and the philosophy of mind. In H. Feigl \& M. Scriven (eds.) Minnesota studies in the philosophy of science Vol. I. Minneapolis: University of Minnesota Press, pp. 253-329.

Sorel, T. (2018). Experimental philosophy and the history of philosophy. British Journal for the History of Philosophy, 26(5), 829-849.

Sosa, E. (2006). Experimental philosophy and philosophical intuition. Philosophical Studies, 132(1), 99-107.

Starmans, C., \& Friedman, O. (2012). The folk conception on knowledge. Cognition, 124, 272-283.

Strawson, P. (1992). Analysis and metaphysics. An introduction to philosophy. Oxford: Oxford University Press.

Swain, S., Alexander, J., \& Weinberg, J. (2008). The instability of philosophical intuitions: Running hot and cold on truetemp. Philosophy and Phenomenological Research, 76(1), 138-155.

Tobia, K., Buckwalter, W., \& Stich, S. (2013). Moral intuitions: Are philosophers experts? Philosophical Psychology, 26(5), 629-638.

Tooby, J., \& DeVore, I. (1987). The reconstruction of hominid behavioral evolution through strategic modeling. In W. G. Kinzey (Ed.), Primate models of hominid behavior (pp. 183-237). Albany: Suny Press.

Varela, F., Thompson, E., \& Rosch, E. (1991). The embodied mind: Cognitive science and human experience. Cambridge MA: MIT Press.

von Uexküll, J. (1926). Theoretical biology. New York: Harcourt, Brace \& Co..

Weinberg, J. (2007). How to challenge intuitions empirically without risking skepticism. Midwest Studies in Philosophy, 31, 318-343.

Weinberg, J., Nichols, S., \& Stich, S. (2001). Normativity and epistemic intuitions. Philosophical Topics, 29, 429-460.

Werner, K. (2016). What is it like to be the metaphysical subject? An essay on early Wittgenstein, our epistemic position, and beyond, Philosophia., 44, 921-946. https://doi.org/10.1007/s11406-016-9693-z.

Werner, K. (2017). Metaphilosophy of mind: How do minds investigate minds? Refutation of the Theocentric View, Integrative Psychological and Behavioral Science, 51, 120-140.

Werner, K. (2018). Enactivism and construction of the cognitive niche. Synthese, 1-29. https://doi.org/10.1007 /s11229-018-1756-1.

Williamson, T. (2004). Philosophical 'intuitions' and Scepticism about judgment. Dialectica, 58, 109-153.

Williamson, T. (2007). The philosophy of philosophy. Oxford: Blackwell Publishing.

Williamson, T. (2011). Philosophical expertise and the burden of proof. Metaphilosophy, 42, 215-229.

Wiśniewski, A. (1995). The posing of questions. Logical foundations of Erotetic inferences. Dordrecht: Springer.

Wittgenstein, L. (1922). Tractatus logico-philosophicus. London: Kegan Paul. Quotations from: L. Wittgenstein, Tractatus Logico-Philosophicus. Mineola, NY: Dover Publications 1999.

Wittgenstein, L. (1953). Philosophical investigations. Oxford: Blackwell.

Woolfolk, L. R. (2013). Experimental philosophy: A methodological critique. Metaphilosophy, 44(1-2), 7987.

Zahavi, D. (2003). Husserl's phenomenology. Stanford CA: Stanford University Press.

Publisher's Note Springer Nature remains neutral with regard to jurisdictional claims in published maps and institutional affiliations. 